\title{
Multidimensional Self-Concept in Elementary Education: Sport Practice and Gender
}

\author{
Diana Amado-Alonso 1 (1), Santiago Mendo-Lázaro ${ }^{2, *}$ (1) , Benito León-del-Barco ${ }^{2, *(1)}$, \\ Mario Mirabel-Alviz ${ }^{2}$ and Damián Iglesias-Gallego ${ }^{3}$ (i) \\ 1 Centre for Sport Studies, Physical Education Area, Rey Juan Carlos University, Alcorcón, \\ 28922 Madrid, Spain; diana.amado@urjc.es \\ 2 Department of Psychology and Anthropology, Teacher Training College, University of Extremadura, \\ 10071 Cáceres, Spain; mirabelalviz@gmail.com \\ 3 Department of Didactic of Musical, Plastic and Corporal Expression, Teacher Training College, University of \\ Extremadura, 10071 Cáceres, Spain; diglesia@unex.es \\ * Correspondence: smendo@unex.es (S.M.-L.); bleon@unex.es (B.L.-d.-B.); \\ Tel.: +034-927-257-049 (S.M.-L. \& B.L.-d.-B.)
}

Received: 3 July 2018; Accepted: 3 August 2018; Published: 8 August 2018

\begin{abstract}
Background: The purpose of this study was to analyse the relation between the number of hours of organized sports practice and self-concept, considered from a multidimensional approach (physical, emotional, academic, social and family self-concept). The relation between these variables as a function of gender was also investigated. Methods: We used a sample of 840 students from fifth and sixth grade of Elementary Education (494 boys and 346 girls), aged 9 to 12 years, from Spain. To assess the students' self-concept, we used the AF- 5 Self-Concept Form 5 questionnaire. Results: The results show that children who practice organized sport, present a better physical self-concept $(0 \mathrm{~h}$ a day $[\mathrm{h} / \mathrm{d}]: \mathrm{M}=5.20, \mathrm{SD}=1.82 ; 1 \mathrm{~h} / \mathrm{d}: \mathrm{M}=5.90, \mathrm{SD}=1.82 ; 2 \mathrm{~h} / \mathrm{d}: \mathrm{M}=5.99, \mathrm{SD}=1.56 ; 3 \mathrm{~h} / \mathrm{d}$ : $\mathrm{M}=6.00, \mathrm{SD}=1.42)$. Boys present a higher emotional self-concept than girls $(p<0.05)$. Moreover, children's sports practice is beneficial for the academic and family self-concept but in the case of girls, a high number of hours of daily practice may be decreasing these potential benefits. Conclusions: The findings suggest that organized sports practice could have a positive effect on self-concept. We underline the importance of encourage children to practice sport and paying particular attention to gender differences in the development of the emotional self-concept during elementary education.
\end{abstract}

Keywords: sport practice; self-concept; childhood; gender

\section{Introduction}

The term self-concept is increasingly more important within the field of personality, both from an affective and an emotional perspective [1,2]. To analyse this psychological variable, it is very interesting to return to the basic cognitive processes of childhood, as they undergo a great evolution after the age of 6 until the end of adolescence [3]. Between ages 6 and 12, children attend compulsory education, and, at this stage, socialization is promoted because children not only develop in the family environment, instead, they also begin to get to know their peers, which allows them to relate to them through games, interactions and so forth. Their participation in new situations and the link between affectivity and the environment will lead to the creation of the child's personality [4].

In this vein, the self-concept is one of the most important outcomes of the processes of education and socialization. Self-concept has been defined as the perceptions that people have about themselves, formed through the interpretation of their own experience and of the environment, particularly influenced by significant others' reinforcements and feedback, as well as by their own cognitive mechanisms, such as causal attributions [5]. 
Self-concept it is not one-dimensional but it is a multidimensional construct (academic, social, family, emotional and physical dimensions) [5]: academic, measuring the perception of the self-efficacy of learning; social, which is related to the significance that the individual's behaviour has for others; family, concerning the family dynamics and relationships; emotional, concerning the most subjective and intimate components; and physical, measuring the fundamental incidence of the individual's aptitudes and general appearance.

In all areas of the human being, the one's self-concept is extremely important but especially for children and youngsters $[3,6]$. Thus, the daily feelings and emotions experienced by children play a vital role in the development of the self-concept, which is subjective and changing, based on the external reality and on their position in other broader contexts $[7,8]$. This will condition children's psychological balance, their relationship with others and their performance in different areas of their lives.

The necessity of studying the relationship of physical activity on self-concept is that these contexts are none other than those in which the child develops, among which we would like to analyse the practice of sports as a means to improve children's socialization and mental processes. Indeed, it has been shown that the practice of physical-sports activity produces psychosocial improvements in cognitive vitality and mood [9,10], lower levels of anxiety [11,12], self-concept and self-esteem $[13,14]$ and it even prevents and reduces clinical depression [15-17]. Some research also indicates better levels of health-related quality of life and satisfaction with life in people whose habits include physical-sport activity, regardless of their life stage [18-20].

However, at the childhood stage, the family influence mostly determines children's sports practice. Parents' more or less positive behaviours and attitudes activity in general and the way they conceive their children's physical activity in particular determine the family sport climate [21]. The importance granted by adolescents to sports and their level of commitment to sports activities or their specific self-perceptions are related to family sports climate and, therefore, to adolescents' sports experience.

More specifically, it has been shown that self-concept is a factor associated with physical and sporting activity [22,23], so that those who regularly practice sport have a higher self-concept [24], particularly the physical self-concept $[25,26]$ but also with all the self-concept dimensions [27]. But we would like to analyse the relation between the number of hours of organized sports practice and self-concept as a function of gender.

With regard to gender, the psychological representation of gender as a social category provides a lens through which we perceive others and define ourselves [28]. In fact, gender is one of children's first distinctions of social groups. They learn to categorize others based on gender, associating different traits, attitudes and activities with the masculine or feminine gender $[29,30]$. Therefore, there are clear gender differences in children's self-concept, which, for social and cultural reasons, manifest in girls' greater concern about their body and image, in their being more critical towards their bodies and more involved in their physical appearance than boys [31,32]. In this sense, authors like Padilla-Carmona et al. [33] state that, among other reasons, this may be due to the strong pressure from the media concerning female aesthetic models that are unreachable.

Thus, this work aims to examine in greater depth the relationship between the practice of physical-sport activity and self-concept, understood as a multidimensional term. More specifically, to determine whether the number of hours of organized sports practice-that is, continuous, formal and institutionalized sports practice-affects children's self-concept in any of its dimensions (physical, emotional, academic, social and family). Moreover, given the gender differences usually associated with self-concept, we aim to determine the relation between the target variables of the study as a function of gender and to suggest guidelines for the development of self-concept.

\section{Methods}

The current research was done with a quantitative methodology and a cross-sectional design. 


\subsection{Ethics Statement}

Insofar as ethical rules are concerned, the study previously received the approval of the Ethics Committee of the University of Extremadura. All participants were treated in agreement with the ethical guidelines of the American Psychological Association with respect to consent, confidentiality and anonymity of the answers. Before carrying out the research study, all those involved were informed about the process that they were going to follow, placing emphasis on the fact that participation was voluntary and that the data would be dealt with confidentially. Moreover, an informed written consent was obtained from the children, parents and the head teachers of the schools on the behalf of the children involved in the study.

\subsection{Participants}

Participants in the investigation were 840 students from 5th and 6th grade of Elementary Education, 494 boys and 346 girls, aged between 9 and 12 years $(M=10.76, S D=1.11)$. The participants were from eight public schools of Extremadura (Spain), which promoted the practice of organized team sports of moderate intensity. Generally, they practiced two hours of compulsory physical education at school, according to the Spanish educational system. In physical education classes the practice of physical activity is varied and has an educational purpose, away from organized sports. However, the practice of extracurricular sports and organized sports is not compulsory, it is usually aimed at performance and competition and, on occasion, a fee must be paid in order to compete. In this study, children practiced mainly team sports of moderate intensity (e.g., basketball, football, handball, volleyball). Sample selection was done by multistage cluster sampling, randomly selecting the groups in the schools, in the previously mentioned courses of Elementary Education. There were no drop-outs.

\subsection{Instruments}

Self-concept. With the intention of evaluating the children's self-concept, we administered the AF-5 Self-Concept Form 5 questionnaire [34] previously validated in Elementary Education [35]. This questionnaire was selected because we consider the self-concept as an entity with multiple facets or conceptions in which some aspects are changing and malleable. Thus, we attempt to explain and provide a differential structure to measure and reflect the diversity of the behaviour related to self-concept. The questionnaire is based on [5] theoretical model of the multidimensional self-concept and consists of five subscales containing 6 items each: Academic (e.g., "I do my homework well"), Social (e.g., "I make friends easily"), Family (e.g., "I'm criticized a lot at home"), Emotional-These items should be coded in reverse so that higher scores indicate more positive emotional intensity-(e.g., "I am afraid of some things") and Physical (e.g., "I care for myself physically"). The degree of agreement with the statements of this items were rated on a 99-point scale, ranging from 1 (strongly disagree) to 99 (strongly agree).

The Cronbach alpha $(\alpha=0.80)$ and the composite reliability $(C R=0.83)$ coefficients show adequate global reliability and average variance extracted $(\mathrm{AVE}=0.55)$. Likewise, the factors of the questionnaire also present adequate reliability and AVE $\geq 0.50$ (Academic factor: $\alpha=0.82, \mathrm{CR}=0.83, \mathrm{AVE}=0.57$; Social factor: $\alpha=0.78, \mathrm{CR}=0.79, \mathrm{AVE}=0.52$; Family factor: $\alpha=0.80, \mathrm{CR}=0.78, \mathrm{AVE}=0.51$; Emotional factor: $\alpha=0.74, \mathrm{CR}=0.79, \mathrm{AVE}=0.50$; Physical factor: $\alpha=0.79, \mathrm{CR}=0.81, \mathrm{AVE}=0.53$ ). Practice of physical-sport activity. The practice of physical-sport activity was assessed in terms of organized sport due to the commitment and assiduity which it requires [36]. Organized sport is institutionalized and recognized, carried out according to the rules and regulation of a Federation and developed through a series of official trainings and competitions [37]. To measure this variable, we designed two questions: How many days a week do you practice organized sport? How many hours a day do you practice organized sport? In this way, the participants were classified according to the average of the number of daily hours expended into organized sports practice (divided into four levels: $0 \mathrm{~h}$, $1 \mathrm{~h}, 2 \mathrm{~h}, 3$ or more hours). A practice frequency of up to $2 \mathrm{~h}$ a day was considered normal or usual 
for practice of organized physical-sport activity, because this type of practice is also characterized by a greater sporting motivation [38], frequency and intensity, known as competitiveness or sporting commitment [36,37], whereas 3 or more hours a day was considered high, very specialized practice.

\subsection{Procedure}

We followed a protocol to ensure that data collection was carried out similarly throughout the process. First, we contacted each of the schools and requested a meeting with the school director to answer any questions about aims, goals, time and courses that could be involved in the research. After they accepted the proposal, the head of studies set up a meeting with the teachers and we proposed a suitable schedule for the administration of the tests.

Prior to the collective administration of the questionnaires during the agreed schedules, the main researcher briefly explained the procedure, as well as the instructions to complete the questionnaires. The administration lasted approximately 30 to $40 \mathrm{~min}$ for each class and the main investigator was present at all times to clarify any doubts that could arise during the process.

\subsection{Data Analysis}

The factorial structure of the AF-5 was assessed with Cronbach's alpha, CR and AVE. By means of the chi-square test, we determined the variance/invariance of the distribution of the participants by gender as a function of the number of hours of practice. To determine the possible effects of practicing or not practicing organized sport, as well as the number of hours of practice and gender on self-concept, we performed multivariate analysis of variance (MANOVA), in which the dependent variables were the scores in the five subscales of theAF- 5 and the independent variables were the number of hours of organized sports practice and the children's gender. The assumptions of normality, randomization and homoscedasticity were confirmed through the Kolmogorov-Smirnov, Rachas and Levene tests, respectively. Effect size differences were calculated with Eta-squared $(\eta)$ and Hedges' $g$ for group differences (e.g., boy vs. girl) when appropriate.

\section{Results}

Table 1 presents the means and standard deviations obtained in the AF- 5 as a function of the number of hours of practice and participants' gender.

Regarding the distribution of the participants according to the number of hours a day $(\mathrm{h} / \mathrm{d})$ of sports practice and gender: $0 \mathrm{~h} / \mathrm{d}$ : girls $\mathrm{N}=114(33 \%)$, boys $\mathrm{N}=99(20 \%) ; 1 \mathrm{~h} / \mathrm{d}$ : girls $\mathrm{N}=121(35 \%)$, boys $\mathrm{N}=163(33 \%) ; 2 \mathrm{~h} / \mathrm{d}$ : girls $\mathrm{N}=80(23 \%)$, boys $\mathrm{N}=178(36 \%) ; 3 \mathrm{~h} / \mathrm{d}$ : girls $\mathrm{N}=31(9 \%)$, boys $\mathrm{N}=54(11 \%)$, there were gender differences, $\chi^{2}(1, \mathrm{~N}=420)=22.356, p<0.001$, in the $0 \mathrm{~h} / \mathrm{d}$ and $2 \mathrm{~h} / \mathrm{d}$ groups of organized sports practice.

Table 1. Means and standard deviations, hours/day of organized sports practice and gender as a function of Self-concept.

\begin{tabular}{cccccccc}
\hline \multirow{2}{*}{ Self-Concept Hours/Day } & \multicolumn{2}{c}{ Girls } & \multicolumn{2}{c}{ Boys } & \multicolumn{2}{c}{ Total } \\
\cline { 3 - 8 } & & $\boldsymbol{M}$ & $\boldsymbol{S D}$ & $\boldsymbol{M}$ & $\boldsymbol{S D}$ & $\boldsymbol{M}$ & $\boldsymbol{S D}$ \\
\hline \multirow{4}{*}{ Academic } & 7.45 & 2.26 & 6.46 & 2.06 & 6.97 & 2.22 \\
& 1 & 7.44 & 1.93 & 7.68 & 1.56 & 7.59 & 1.72 \\
& 2 & 7.23 & 2.42 & 7.31 & 1.93 & 7.29 & 2.09 \\
& 3 or $>$ & 6.23 & 1.66 & 7.36 & 1.77 & 6.96 & 1.80 \\
& Total & 7.28 & 2.17 & 7.26 & 1.88 & 7.27 & 2.00 \\
\hline
\end{tabular}


Table 1. Cont.

\begin{tabular}{cccccccc}
\hline \multirow{2}{*}{ Self-Concept Hours/Day } & \multicolumn{2}{c}{ Girls } & \multicolumn{2}{c}{ Boys } & \multicolumn{2}{c}{ Total } \\
\cline { 2 - 7 } & 0 & 7.59 & 1.44 & 7.34 & 1.49 & 7.47 & 1.47 \\
\multirow{5}{*}{ Social } & 1 & 7.64 & 1.30 & 7.39 & 1.62 & 7.49 & 1.50 \\
& 2 & 8.03 & 1.24 & 7.34 & 1.73 & 7.55 & 1.63 \\
& 3 or $>$ & 7.61 & 1.49 & 7.86 & 1.21 & 7.77 & 1.31 \\
& Total & 7.71 & 1.36 & 7.41 & 1.60 & 7.53 & 1.51 \\
\hline \multirow{5}{*}{ Emotional } & 0 & 5.19 & 1.96 & 5.44 & 2.28 & 5.31 & 2.12 \\
& 1 & 5.17 & 2.13 & 5.61 & 2.00 & 5.37 & 2.06 \\
& 2 & 5.18 & 2.43 & 5.67 & 1.96 & 5.58 & 2.11 \\
& 3 or $>$ & 4.74 & 2.12 & 5.42 & 1.80 & 5.18 & 1.93 \\
Family & Total & 5.09 & 2.14 & 5.64 & 2.02 & 5.40 & 2.08 \\
\hline & 0 & 8.54 & 1.82 & 7.92 & 1.83 & 8.25 & 1.85 \\
& 1 & 8.64 & 1.48 & 8.59 & 1.38 & 8.61 & 1.42 \\
& 2 & 9.02 & .912 & 8.32 & 1.97 & 8.53 & 1.74 \\
& 3 or $>$ & 7.75 & 2.10 & 8.18 & 1.87 & 8.03 & 1.95 \\
Physical & Total & 8.62 & 1.59 & 8.31 & 1.76 & 8.43 & 1.70 \\
\hline & 0 & 5.26 & 1.88 & 5.14 & 1.77 & 5.20 & 1.82 \\
& 1 & 5.80 & 1.73 & 5.98 & 1.44 & 5.90 & 1.56 \\
& 2 & 5.67 & 1.84 & 6.12 & 1.62 & 5.99 & 1.70 \\
& 3 or $>$ & 6.15 & 1.36 & 5.92 & 1.46 & 6.00 & 1.42 \\
& Total & 5.62 & 1.79 & 5.85 & 1.62 & 5.76 & 1.69 \\
\hline
\end{tabular}

A multivariate analysis of the variance (MANOVA) was carried out to analyse the effect of number of hours of organized sports practice and gender on self-concept (AF-5). MANOVA revealed significant multivariate principal effects, although with a small effect sizes, on number of hours of organized sports practice (Wilks $\lambda=0.922, \mathrm{~F}(15,1977)=3.948, p<0.001, \eta=0.027$ ), gender (Wilks $\lambda=0.976$, $\mathrm{F}(5,716)=3.457, p=0.004, \eta=0.024$ ) and on the interaction between both variables (Wilks $\lambda=0.946$, $\mathrm{F}(10,1584)=2.702, p<0.001, \eta=0.019)$.

The univariate contrasts, the MANOVA showed a significant main effect with a small effect sizes of the number of hours of organized sports practice on academic, $\mathrm{F}(3,720)=4.563, p=0.004$, $\eta=0.019$, family, $\mathrm{F}(3,720)=4.704, p=0.003, \eta=0.019$ and physical self-concept, $\mathrm{F}(3,720)=8.427$, $p<0.001, \eta=0.034$ but not on social, $\mathrm{F}(3,720)=1.072, p=0.360, \eta=0.004$, or emotional self-concept, $\mathrm{F}(3,720)=0.833, p=0.476, \eta=0.003$.

Participants' gender had a significant main effect with a small effect sizes on emotional self-concept, $\mathrm{F}(1,720)=4.701, p=0.030, \eta=0.006$, with no other significant main effects on academic, $\mathrm{F}(1,720)=0.468, p=0.494, \eta=0.001$, social, $\mathrm{F}(1,720)=3.262, p=0.071, \eta=0.005$, family, $\mathrm{F}(1,720)=2.613$, $p=0.106, \eta=0.004$, or physical self-concept, $\mathrm{F}(1,720)=0.232, p=0.630, \eta=0.001$. In addition, the Hours $X$ Gender interaction was significant for the variables of academic, $\mathrm{F}(3,720)=6.131, p<0.001, \eta=0.025$ and family self-concept, $\mathrm{F}(3,720)=2.921, p=0.033, \eta=0.012$.

Multiple comparisons of the number of hours of organized sports practice (Table 2) showed that: (1) Children who practiced one hour of organized sport achieved higher scores with a small effect sizes in academic self-concept than those who did not practice $(p=0.010 ; \mathrm{g}=0.32)$ it or they did it three or more hours a day $(p=0.030 ; \mathrm{g}=0.37)$; (2) Children who practiced three or more hours a day of organized sport achieved lower scores with a small effect sizes in family self-concept than those who practiced one $(p=0.031 ; \mathrm{g}=0.37)$ or two $(p=0.020 ; \mathrm{g}=0.28)$ hours a day; (3) Children who practiced one hour, two hours, or three or more hours, of organized sport achieved higher scores with effect sizes in the small-to-medium range ( $p \leq 0.003 ; 1 \mathrm{~h}: \mathrm{g}=0.42 ; 2 \mathrm{~h}: \mathrm{g}=0.45 ; \geq 3 \mathrm{~h}: \mathrm{g}=0.46)$ in physical self-concept than those who did not practice. 
Table 2. Post-hoc comparisons (Bonferroni) of scores on the AF-5 scale, based on hours/day of organized sports practice.

\begin{tabular}{|c|c|c|c|c|c|c|c|c|c|c|c|}
\hline \multicolumn{12}{|c|}{ Self-Concept } \\
\hline & & \multicolumn{2}{|c|}{ Academic } & \multicolumn{2}{|c|}{ Social } & \multicolumn{2}{|c|}{ Emotional } & \multicolumn{2}{|c|}{ Family } & \multicolumn{2}{|c|}{ Physical } \\
\hline \multicolumn{2}{|c|}{ Hours/day } & $M D(\mathrm{I}-\mathrm{J})$ & $S E$ & $M D(\mathrm{I}-\mathrm{J})$ & $S E$ & $M D(\mathrm{I}-\mathrm{J})$ & $S E$ & $M D(\mathrm{I}-\mathrm{J})$ & $S E$ & $M D(\mathrm{I}-\mathrm{J})$ & $S E$ \\
\hline \multirow{3}{*}{0} & 1 & -0.608 * & 0.193 & -0.051 & 0.148 & -0.023 & 0.204 & -0.383 & 0.165 & $-0.690 *$ & 0.164 \\
\hline & 2 & -0.316 & 0.203 & -0.225 & 0.155 & -0.209 & 0.214 & -0.434 & 0.174 & -0.699 * & 0.172 \\
\hline & 3 or $>$ & 0.159 & 0.279 & -0.272 & 0.214 & 0.234 & 0.295 & 0.270 & 0.239 & $-0.837^{*}$ & 0.237 \\
\hline \multirow[b]{2}{*}{1} & 2 & 0.291 & 0.193 & -0.173 & 0.148 & -0.186 & 0.204 & -0.051 & 0.165 & -0.009 & 0.163 \\
\hline & 3 or $>$ & $0.767^{*}$ & 0.272 & -0.221 & 0.209 & 0.256 & 0.288 & $0.653 *$ & 0.233 & -0.147 & 0.231 \\
\hline 2 & 3 or $>$ & 0.475 & 0.279 & -0.047 & 0.214 & 0.443 & 0.295 & $0.704 *$ & 0.239 & -0.138 & 0.237 \\
\hline
\end{tabular}

Multiple comparisons of the number of hours of organized sports practice and gender (Table 3) showed that: (1) Boys achieved higher scores with a small effect sizes $(p=0.030 ; \mathrm{g}=0.26)$ in emotional self-concept than girls; (2) Among children who did not practice organized sports, girls scored higher than boys, with effect sizes in the small-to-medium range in academic $(p=0.001 ; \mathrm{g}=0.45)$ and small in the family $(p=0.011 ; g=0.34)$ self-concept; (3) Among those who practiced two hours a day of organized sports, girls scored higher than boys with effect sizes in the small-to-medium range $(p=0.002 ; \mathrm{g}=0.43)$ in social self-concept; (4) Among those who practice three or more hours a day of organized sports, boys scored higher than girls with medium effect sizes $(p=0.019 ; \mathrm{g}=0.65)$ in academic self-concept.

Table 3. Post-hoc comparisons (Bonferroni) of scores on the AF-5 scale, based on hours/day of organized sports practice and gender.

\begin{tabular}{|c|c|c|c|c|c|c|c|c|c|c|c|c|}
\hline \multicolumn{13}{|c|}{ Self-concept } \\
\hline & & & \multicolumn{2}{|c|}{ Academic } & \multicolumn{2}{|c|}{ Social } & \multicolumn{2}{|c|}{ Emotional } & \multicolumn{2}{|c|}{ Family } & \multicolumn{2}{|c|}{ Physical } \\
\hline \multicolumn{3}{|c|}{ Gender*Hour/Day } & $M D(\mathrm{I}-\mathrm{J})$ & $S E$ & $M D(\mathrm{I}-\mathrm{J})$ & $S E$ & $M D(\mathrm{I}-\mathrm{J})$ & $S E$ & $M D(\mathrm{I}-\mathrm{J})$ & $S E$ & $M D(\mathrm{I}-\mathrm{J})$ & $S E$ \\
\hline Girls & Boys & 0 & $0.995 *$ & 0.287 & 0.252 & 0.220 & -0.250 & 0.304 & $0.625 *$ & 0.246 & 0.119 & 0.244 \\
\hline Girls & Boys & 1 & -0.250 & 0.258 & 0.244 & 0.198 & -0.342 & 0.273 & 0.044 & 0.221 & -0.182 & 0.218 \\
\hline Girls & Boys & 2 & -0.087 & 0.286 & 0.694 * & 0.219 & -0.289 & 0.302 & 0.198 & 0.245 & -0.447 & 0.242 \\
\hline Girls & Boys & 3 or $>$ & $-1.123 *$ & 0.479 & -0.251 & 0.368 & -0.676 & 0.507 & -0.428 & 0.411 & 0.233 & 0.406 \\
\hline Girls & Boys & Total & -0.116 & 0.170 & 0.235 & 0.130 & -0.389 * & 0.179 & 0.235 & 0.145 & -0.069 & 0.144 \\
\hline
\end{tabular}

* The mean difference is significant at the 0.05 level.

Likewise, multiple comparisons of the gender and number of hours of organized sports practice (Table 4) showed that: (1) Girls who practiced three or more hours a day obtained lower scores with medium effect sizes in academic self-concept than the rest of girls $(p<0.05 ; 0 \mathrm{~h}: \mathrm{g}=0.56,1 \mathrm{~h}: \mathrm{g}=0.64$, $2 \mathrm{~h}: \mathrm{g}=0.44)$ and higher scores with medium effect sizes in physical self-concept than girls who not practice organized sports $(p=0.049 ; \mathrm{g}=0.50)$; (2) Boys who did not practice organized sports obtain lower scores with effect sizes medium and small-medium range in academic self-concept than the rest of the boys ( $p \leq 0.003 ; 1 \mathrm{~h}: \mathrm{g}=0.69,2 \mathrm{~h}: \mathrm{g}=0.43, \geq 3 \mathrm{~h}: \mathrm{g}=0.46)$ and lower scores with medium effect sizes in physical self-concept than boys who practiced one $(p=0.001 ; \mathrm{g}=0.53)$ or two $(p<0.001$; $\mathrm{g}=0.58)$ hours a day. 
Table 4. Post-hoc comparisons (Bonferroni) of scores on the AF-5 scale, based on the interaction between the gender and the hours/day of organized sports practice.

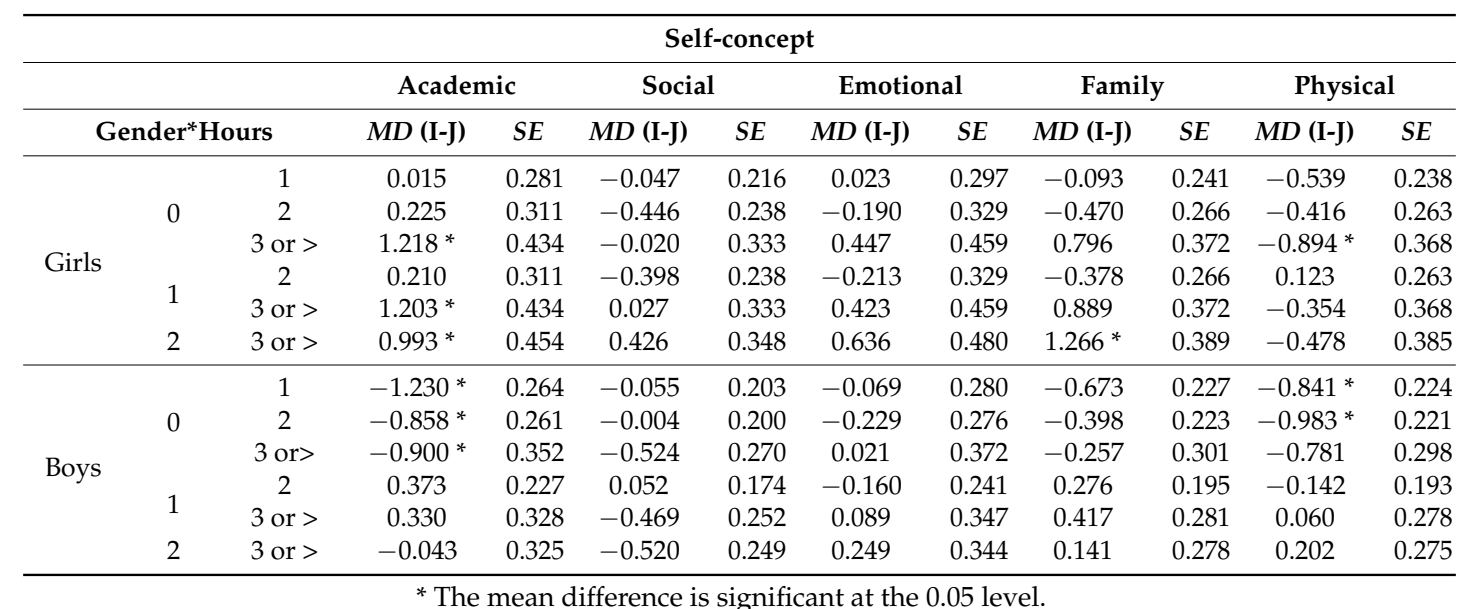

\section{Discussion}

The main goal of this study was to analyse the relationship between the hours of organized sports practice and self-concept from a multidimensional approach (physical, emotional, academic, social and family self-concept), observing, at the same time, the role played by gender in the relationship between these variables.

Accordingly, after analysing the results, the discussion and interpretation is structured along three main lines. Firstly, the results of the study show that boys and girls who practice one, two, or three or more hours of organized sport obtain higher scores on physical self-concept that those who do not practice. This could indicate that children who are physically active perceive themselves as physically better than those who do not practice any physical-sport activity. Therefore, through the establishment of healthy habits of sports practice, children can come to feel valued and satisfied with their physical features. These results are consistent with other studies that have indicated that physically active participants present a better physical self-concept $[13,39,40]$.

In second place, the results indicate that boys obtain higher scores in emotional self-concept than girls. Similar results were found in studies such as those of [41] with a sample of 1235 students ( 684 boys and 551 girls) aged between 11 and 14 years and [33] with a sample of 415 students (130 boys and 285 girls) aged 15 to 16 . According to these studies, these results could indicate that, whereas boys are more personally adapted, girls may be likely to suffer from anxiety.

Following this line and taking into account that the emotional self-concept refers to the most subjective and intimate components, these results might be explained by women's role in society. Thus, the observation of what is going on around them leads girls to deduce that their social role is secondary to that of the boys [33]. The so-called hypothesis of intensification of gender was constructed under these assumptions [42]. According to this hypothesis, early adolescence is a period in which adolescents become more intensely aware of the traditional roles assigned to each sex. Girls may feel the limitations that are associated with being a woman in our society [33].

Finally, the third line of results found that girls who do not practice organized sport or who practice one or two hours a day obtain higher scores in family and academic self-concept than those who practice more frequently (for three or more hours a day). However, in the case of boys, the opposite was observed. The results suggest that sport may be beneficial for girls' academic and family self-concept but only up to a certain frequency of practice hours. This could be explained because girls tend to grant more importance to the academic and family context than to sports, whereas the opposite occurs with boys, which is mainly due to social and cultural aspects and to sexist stereotypes [43]. Boys and girls are aware of the social expectations concerning their participation in sports and physical activities. 
Boys tend to show a desire for physical contact sports as central experiences to establish an acceptable masculine identity [44], whereas girls often encounter a less favourable family sports climate than boys [21] and they may be pressured into showing preference for other activities.

Previous research has shown that girls feel greater family attachment than boys [45] and may therefore perceive a higher family self-concept. In fact, various studies highlight that, at these stages, the family nucleus is essential for motivation, behaviour and the acquisition of values [46,47]. Moreover, the differences could be justified by the different treatment received from the parents [41]. In this sense, the behaviour of girls at home better satisfies the expectations of mothers and fathers (help in domestic tasks, not being late...), feeling more accepted by them and, in this way, promoting the development of a higher family self-concept [33].

On the other hand, at academic level, studies have shown that girls are more self-demanding academically than boys, which usually makes them try harder and get better grades, thus possibly increasing their academic self-concept [48].

The main limitation of this study is the use of questionnaires as the only method of data collection, as questionnaires are not very appropriate to deal with participants' potential response bias. The lack of a measurement of the children's academic performance prevented us from relating their academic self-concept to their real performance. Therefore, future studies should include this measure to be able to observe the relationships between the children's perception and their academic reality. It would also be very interesting to perform a quasi-experimental study, introducing sports practice as an independent variable in the design and observing its influence on self-concept and analysing the evolution of these variables as a function of gender.

Another aspect that needs to be considered is that the results presented in this study do not rule out reverse causality, for example, the stronger sports self-concept might drive willingness to spend more time on sports. Thus, new studies should be conducted to more consistently establish these relationships.

\section{Conclusions}

Lastly, as the main conclusions of this work, we note: (a) boys and girls who are physically active perceive themselves as physically better than those who do not practice a physical-sport activity and, therefore, they present a better physical self-concept. Therefore, we suggest the promotion of physical activity at these ages. However, what has been found in relation to other studies is that the physical self-concept of boys is superior to that of girls; (b) The differences between boys and girls in academic self-concept show that, at the stage of Elementary Education, it is important to place more emphasis on the emotional self-concept from a gender perspective. Teachers and family should become aware of the existing gender stereotypes and prejudices when dealing with the capacity to give an adequate emotional response to external stimuli, or the develop of the emotional intelligence; and (c) Although children's sports practice may be beneficial for the academic and family self-concept, in the case of girls, a high number of hours of daily practice may be decreasing these potential benefits.

However, although the findings of this research show the relationship between the practice of physical activity and the different dimensions of self-concept in children, new studies should be conducted to more consistently demonstrate the relationship between self-concept and the practice of physical activity.

\section{What Does This Article Add?}

This article highlights the importance of sports practice and gender in the study of variables that affect or do not affect the self-concept in childhood, because this important variable affect children's psychological balance, their relationship with others and their performance in different areas of their lives.

These contexts are none other than those in which the child develops, among which we analyse the sports practice as a means to improve children's socialization and mental processes. With regard 
to gender, the psychological representation of gender as a social category provides a lens through which we perceive others and define ourselves. Children's learn to categorize others based on gender, associating different traits, attitudes and activities with the masculine or feminine gender. Therefore, there are clear gender differences in children's self-concept.

In this regard, this article shows that organized sports practice could have a positive effect on self-concept in childhood, mainly at physical, academic and familiar level. However, parents and teachers must supervise the number of hours of practice in girls because too much hours could affect their academic and familiar self-concept. Moreover, they must increase the emotional self-concept in girls, by developing the ability to give an appropriate emotional response to external stimuli, the emotional intelligence. Thus, we underline the importance of encourage children to practice sport and paying particular attention to gender differences in the development of self-concept during Elementary Education.

However, it is necessary to take in account that the combination of sports practice and outside sports physical activity should be at least $60 \mathrm{~min}$ a day, as recognized by WHO. In spite of this, it could be interesting to know what would be the amount of physical activity adequate to achieve effects beyond the purely physical, testing different instruments and criteria to those used in this study.

Author Contributions: Conceptualización, D.A.-A. and D.I.-G.; Methodology, S.M.-L. and B.L.-d.-B.; Formal Analysis, S.M.-L.; Investigation, B.L.-d.-B. and M.M.-A.; Data Curation, S.M.-L. and M.M.-A.; Writing-Original Draft Preparation, D.A.-A., S.M.-L. and M.M.-A.; Writing-Review \& Editing, D.A.-A., S.M.-L. and D.I.-G.; Supervision, B.L.-d.-B. and D.I.-G.

Acknowledgments: The authors would like to thank the participation of teachers and pupils in this study.

Conflicts of Interest: The authors declare no conflict of interest.

\section{References}

1. Evans, D.; Dalgleish, T.; Dudas, R.B.; Denman, C.; Howard, M.; Dunn, B.D. Examining the Shared and Unique Features of Self-Concept Content and Structure in Borderline Personality Disorder and Depression. Cogn. Ther. Res. 2015, 39, 613-626. [CrossRef]

2. Vater, A.; Schröder-Abé, M.; Weißgerber, S.; Roepke, S.; Schütz, A. Self-concept structure and borderline personality disorder: Evidence for negative compartmentalization. J. Behav. Ther. Exp. Psychiatry 2015, 46, 50-58. [CrossRef] [PubMed]

3. Blakely-McClure, S.J;; Ostrov, J.M. Relational aggression, victimization and self-concept: Testing pathways from middle childhood to adolescence. J. Youth Adolesc. 2016, 45, 376-390. [CrossRef] [PubMed]

4. Schore, A.N. Affect Regulation and the Origin of the Self: The Neurobiology of Emotional Development; Routledge: Abingdon, UK, 2015.

5. Shavelson, R.J.; Hubner, J.; Stanton, G. Self-concept: Validation of construct interpretations. Rev. Educ. Res. 1976, 1, 407-441. [CrossRef]

6. Steiger, A.E.; Allemand, M.; Robins, R.W.; Fend, H.A. Low and decreasing self-esteem during adolescence predict adult depression two decades later. J. Pers. Soc. Psychol. 2014, 106, 325. [CrossRef] [PubMed]

7. Dasgupta, N. Implicit attitudes and beliefs adapt to situations: A decade of research on the malleability of implicit prejudice, stereotypes and the self-concept. Adv. Exp. Soc. Psychol. 2013, 47, 233-279.

8. Preckel, F.; Niepel, C.; Schneider, M.; Brunner, M. Self-concept in adolescence: A longitudinal study on reciprocal effects of self-perceptions in academic and social domains. J. Adolesc. 2013, 36, 1165-1175. [CrossRef] [PubMed]

9. Biddle, S.J.H.; Fox, K.R.; Boutcher, S.H. Physical Activity and Psychological Wellbeing; Routledge: Abingdon, $\mathrm{UK}, 2000$.

10. Prakash, R.S.; Voss, M.W.; Erickson, K.I.; Kramer, A.F. Physical activity and cognitive vitality. Annu. Rev. Psychol. 2015, 66, 769-797. [CrossRef] [PubMed]

11. Moylan, S.; Eyre, H.A.; Maes, M.; Baune, B.T.; Jacka, F.N.; Berk, M. Exercising the worry away: How inflammation, oxidative and nitrogen stress mediates the beneficial effect of physical activity on anxiety disorder symptoms and behaviours. Neurosci. Biobehav. Rev. 2013, 37, 573-584. [CrossRef] [PubMed] 
12. Rebar, A.L.; Stanton, R.; Geard, D.; Short, C.; Duncan, M.J.; Vandelanotte, C. A meta-meta-analysis of the effect of physical activity on depression and anxiety in non-clinical adult populations. Health Psychol. Rev. 2015, 9, 366-378. [CrossRef] [PubMed]

13. Babic, M.J.; Morgan, P.J.; Plotnikoff, R.C.; Lonsdale, C.; White, R.L.; Lubans, D.R. Physical activity and physical self-concept in youth: Systematic review and meta-analysis. Sports Med. 2014, 44, 1589-1601. [CrossRef] [PubMed]

14. Fox, K.R. Self-esteem, self-perceptions and exercise. Int. J. Sport Psychol. 2000, 31, 228-240.

15. De Mello, M.T.; de Aquino Lemos, V.; Antunes, H.K.M.; Bittencourt, L.; Santos-Silva, R.; Tufik, S. Relationship between physical activity and depression and anxiety symptoms: A population study. J. Affect. Disord. 2013, 149, 241-246. [CrossRef] [PubMed]

16. Knapen, J.; Vancampfort, D.; Moriën, Y.; Marchal, Y. Exercise therapy improves both mental and physical health in patients with major depression. Disabil. Rehabil. 2015, 37, 1490-1495. [CrossRef] [PubMed]

17. Mammen, G.; Faulkner, G. Physical activity and the prevention of depression: A systematic review of prospective studies. Am. J. Prev. Med. 2013, 45, 649-657. [CrossRef] [PubMed]

18. Bhullar, N.; Schutte, N.S.; Malouff, J.M. The Nature of Well-Being: The Roles of Hedonic and Eudaimonic Processes and Trait Emotional Intelligence. J. Psychol. 2013, 147, 1-16. [CrossRef] [PubMed]

19. Gill, D.L.; Hammond, C.C.; Reifsteck, E.J.; Jehu, C.M.; Williams, R.A.; Adams, M.M.; Shang, Y.T. Physical activity and quality of life. J. Prev. Med. Public Health 2013, 46, S28-S34. [CrossRef] [PubMed]

20. Joseph, R.P.; Royse, K.E.; Benitez, T.J.; Pekmezi, D.W. Physical activity and quality of life among university students: Exploring self-efficacy, self-esteem and affect as potential mediators. Qual. Life Res. 2014, 23, 659-667. [CrossRef] [PubMed]

21. Brustad, R.J. Integrating socialization influences into the study of children's motivation in sport. J. Sport Exerc. Psychol. 1992, 14, 59-77. [CrossRef]

22. Mendo, S.; Polo, M.I.; Amado, D.; Iglesias, D.; León, B. Self-concept in childhood: The role of body image and sport practice. Front. Psychol. 2017, 8, 853. [CrossRef] [PubMed]

23. Slutzky, C.B.; Simpkins, S.D. The link between children's sport participation and self-esteem: Exploring the mediating role of sport self-concept. Psychol, Sport Exerc. 2009, 10, 381-389. [CrossRef]

24. Pastor, Y.; Balaguer, I.Y.; García-Merita, M.L. The relationship between self-concept and a healthy lifestyle in adolescence: An exploratory model. Psicothema 2006, 18, 18-24. [PubMed]

25. Knowles, A.; Niven, A.; Fawkner, S.; Henretty, J. A longitudinal examination of the influence of maturation on physical self-perceptions and the relationship with physical activity in early adolescent girls. J. Adolesc. 2009, 32, 555-566. [CrossRef] [PubMed]

26. Lindwall, M.; Hassmén, P. The role of exercise and gender for physical selfperceptions and importance ratings Swedish university students. Scand. J. Med. Sci. Sports 2004, 14, 373-380. [CrossRef] [PubMed]

27. Murgui, S.; García, C.; García, A. Effect of sport practice on the relationship between motor skills, physical self-concept and multidimensional self-concept. Rev. Psicol. Deport. 2016, 25, 19-25.

28. Baron, A.S.; Schmader, T.; Cvencek, D.; Meltzoff, A.N. The gendered self-concept: How implicit gender stereotypes and attitudes shape self-definition. In Gender and Development; Leman, P.J., Tenenbaum, H.R., Eds.; Psychology Press: New York, NY, USA, 2014; pp. 109-132.

29. Croft, A.; Schmader, T.; Block, K.; Baron, A.S. The second shift reflected in the second generation: Do parents gender roles at home predict children's aspirations? Psychol. Sci. 2014, 25, 1418-1428. [CrossRef] [PubMed]

30. Davies, P.G.; Spencer, S.J.; Steele, C.M. Clearing the air: Identity safety moderates the effects of stereotype threat on women's leadership aspirations. J. Pers. Soc. Psychol. 2005, 88, 276-287. [CrossRef] [PubMed]

31. Michael, S.L.; Wentzel, K.; Elliott, M.N.; Dittus, P.J.; Kanouse, D.E.; Wallander, J.L.; Franklin, F.A. Parental and peer factors associated with body image discrepancy among fifth-grade boys and girls. J. Youth Adolesc. 2014, 43, 15-29. [CrossRef] [PubMed]

32. Shriver, L.H.; Harrist, A.W.; Page, M.; Hubbs-Tait, L.; Moulton, M.; Topham, G. Differences in body esteem by weight status, gender and physical activity among young elementary school-aged children. Body Image 2013, 10, 78-84. [CrossRef] [PubMed]

33. Padilla-Carmona, M.T.; García-Gómez, S.; Suárez-Ortega, M. Gender differences in students' general and academic self-concept at the end of compulsory education. Rev. Educ. 2010, 352, 495-515.

34. García, F.; Musitu, G. Autoconcepto Forma 5. AF5. Manual; TEA: Madrid, Spain, 2001. (In Spanish) 
35. Micó-Cebrián, P.; Cava, M.J. Intercultural sensitivity, empathy, self-concept and satisfaction with life in primary school students. Infancia y Aprendizaje 2014, 37, 342-367. [CrossRef]

36. Isorna, M.; Rial, A.; Vaquero-Cristóbal, R. Motivations for practicing sports in federate and non-federate students. RETOS-Neuvas Tendencias en Educacion Fisica, Deporte y Recreacion 2014, 25, 80-84.

37. Blanco, E.; Burriel, J.C.; Camps, A.; Carretero, J.L.; Landaberea, J.A.; Montes, V. Manual de la Organización Institucional del Deporte; Paidotribo: Barcelona, Spain, 2006. (In Spanish)

38. Lochbaum, M.; Zazo, R.; Kazak Çetinkalp, Z.; Wright, T.; Graham, K.A.; Konttinen, N. A meta-analytic review of achievement goal orientation correlates in competitive sport: A follow-up to Lochbaum et al. Kinesiology 2016, 48, 159-173.

39. Liu, M.; Wu, L.; Ming, Q. How does physical activity intervention improve self-esteem and self-concept in children and adolescents? Evidence from a meta-analysis. PLoS ONE 2015, 10, e0134804. [CrossRef] [PubMed]

40. Schranz, N.; Tomkinson, G.; Parletta, N.; Petkov, J.; Olds, T. Can resistance training change the strength, body composition and self-concept of overweight and obese adolescent males? A randomised controlled trial. Br. J. Sports Med. 2014, 48, 1482-1488. [CrossRef] [PubMed]

41. Amezcua, J.A.; Pichardo, M.C. Diferencias de género en autoconcepto en sujetos adolescentes. Anales de Psicología 2000, 16, 207-214.

42. Hill, J.P.; Lynch, M.E. The intensification of gender-related role expectations during early adolescence. In Girls at Puberty: Biological and Psychosocial Perspectives; Brooks-Gunn, J., Petersen, A., Eds.; Springer: Boston, MA, USA, 1983; pp. 201-228.

43. Crain, R.M. The influence of age, race and gender on child and adolescent multidimensional self-concept. In Handbook of Self-Concept. Developmental, Social and Clinical Considerations; Bracken, B.A., Ed.; John Wiley and Sons: Oxford, UK, 1996; pp. 395-420.

44. Chalabaev, A.; Sarrazin, P.; Fontayne, P.; Boiché, J.; Clément-Guillotin, C. The influence of sex stereotypes and gender roles on participation and performance in sport and exercise: Review and future directions. Psychol. Sport Exerc. 2013, 14, 136-144. [CrossRef]

45. Cooper, P.J.; Pauletti, R.E.; Tobin, D.D.; Menon, M.; Menon, M.; Spatta, B.C.; Perry, D.G. Mother-child attachment and gender identity in preadolescence. Sex Roles 2013, 69, 618-631. [CrossRef]

46. Núñez, J.L.; Martín-Albo, J.; Navarro, J.G.; Sánchez, J.M.; González-Cutre, D. Intrinsic motivation and sportmanship: Mediating role of interpersonal relationship. Percept. Mot. Skills 2009, 108, 681-692. [CrossRef] [PubMed]

47. Zurita Ortega, F.; Castro Sánchez, M.; Álvaro González, J.I.; Rodríguez Fernández, S.; Pérez Cortés, A.J. Self-concept, physical activity and family-analysis of a structural equation model. Rev. Psicol. Dep. 2016, 25, 97-104.

48. Jiménez Fernández, C.; Álvarez González, B.; Gil Pascual, J.; Murga Menoyo, M.; Téllez Muñoz, J.; Trillo Miravalles, M. Towards a Socio-cultural Explicative Model of High Achievement and High Ability I: Family Context. Rev. Esp. Orientac. Psicopedag. 2007, 18, 31-46.

(C) 2018 by the authors. Licensee MDPI, Basel, Switzerland. This article is an open access article distributed under the terms and conditions of the Creative Commons Attribution (CC BY) license (http:/ / creativecommons.org/licenses/by/4.0/). 